Research Article

\title{
Comparative study of tramadol and piroxicam as analgesic for postoperative pain in patients operated for inguinal hernia and hydrocele
}

\author{
Ajay Kumar Shukla ${ }^{1}$, Mustafa Raja ${ }^{2}$, Arun Kumar Srivastav ${ }^{1}$
}

\begin{abstract}
${ }^{1}$ Department of Pharmacology, Gandhi Medical College, Bhopal, India,

${ }^{2}$ Department of Pharmacology, L.N. Medical College, Bhopal, India
\end{abstract}

Received: 05 March 2016 Accepted: 18 March 2016

\section{*Correspondence to:}

Dr. Ajay Kumar Shukla, Email: drajay1024@gmail.com

Copyright: (C) the author(s), publisher and licensee Medip Academy. This is an openaccess article distributed under the terms of the Creative Commons Attribution NonCommercial License, which permits unrestricted noncommercial use, distribution, and reproduction in any medium, provided the original work is properly cited.

\begin{abstract}
Background: Pain is usually protective, it warns of tissue damage and prompts treatment but postoperatively, it can delay recovery. Postoperative pain is both distressing and detrimental for the patient. Postoperative pain may be a significant reason for delayed discharge from hospital, increased morbidity and reduced patient satisfaction.
\end{abstract}

Methods: This was a hospital based prospective, randomized, comparative, observational study conducted over a period of one year. Patients operated for hydrocele and inguinal hernia were included in the study after applying the inclusion and exclusion criteria. For the purpose of study, equal numbers of subjects were randomly allocated one of the two analgesic protocols. Pain assessment was done by using visual analog scale (VAS) for the first 72 hours of the postoperative period.

Results: When the drugs were compared individually, piroxicam was superior to tramadol in first 24,48 and 72 hours of postoperative period in case of pain after surgery for hernia. Piroxicam was found to be superior to tramadol in first postoperative 24 hours after surgery for hydrocele with no significant difference first $48 \& 72$ hours of postoperative period. Piroxicam has the advantage of requiring lesser frequency of administration than tramadol due to prolonged duration of action.

Conclusions: Piroxicam provides better and effective analgesia in acute postoperative pain along with the advantage of requiring lesser frequency of administration than tramadol.

Keywords: Analgesic efficacy, Analgesia, Pain assessment, Visual analog scale

\section{INTRODUCTION}

The International Association for the Study of Pain defines "pain as an unpleasant sensory and emotional experience, associated with actual or potential tissue damage or described in terms of such damage". 1

Pain is an unpleasant sensation localized to a part of the body. It is often described in terms of a penetrating or tissue-destructive process (e.g., stabbing, burning, twisting, tearing, squeezing) and/or of a bodily or emotional reaction (e.g., terrifying, nauseating, sickening) Furthermore, any pain of moderate or higher intensity is accompanied by anxiety and the urge to escape or terminate the feeling. These properties illustrate the duality of pain: it is both sensation and emotion. When it is acute, pain is characteristically associated with behavioural arousal and a stress response consisting of increased blood pressure, heart rate, pupil diameter, and plasma cortisol levels. In addition, local muscle contraction (e.g., limb flexion, abdominal wall rigidity) is often present. ${ }^{2}$

Pain is usually protective, it warns of tissue damage and prompts treatment but postoperatively, it can delay recovery. Postoperative pain is both distressing and detrimental for the patient. Postoperative pain may be a significant reason for delayed discharge from hospital, 
increased morbidity and reduced patient satisfaction. ${ }^{3}$ Factors affecting the degree of post-operative pain include the patient's previous experiences and mental preparation (which can be influenced by the surgeon and anesthetist), intra-operative pain management, the nature and duration of surgery, the site and size of the incision and the extent of surgical trauma. ${ }^{4}$

The pain causes the patient to remain immobile, thus becoming vulnerable to deep vein thrombosis (DVT), pulmonary atelectasis, muscle wasting and urinary retention. The aims of postoperative analgesia are to achieve pain relief without nausea and drowsiness and to avoid breakthrough pain during convalescence. ${ }^{5}$

Repair of inguinal hernia and hydrocele are the two common surgeries performed by general surgeons; convalescence time away from work after such surgery constitutes an important loss of income to both individual and nation. ${ }^{6}$

Drugs used for postoperative pain can be grouped as simple analgesics, (e.g., paracetamol), NSAIDs, opioids, and adjuvants (e.g., antiepileptics, antidepressants). The cause of pain must also be considered when selecting treatment. ${ }^{4}$

There is increasing interest in the use of non-steroidal anti-inflammatory drugs (NSAIDs) as analgesics for postoperative pain relief. ${ }^{7}$ The aim of using such drugs is to reduce the requirements for opioids and thereby the frequency of unwanted side-effects, but also to improve the quality of pain relief. ${ }^{8}$

NSAIDs are particularly effective when inflammation has caused sensitization of pain receptors to normally painless mechanical or chemical stimuli. Pain that accompanies inflammation and tissue injury probably results from local stimulation of pain fibres and enhanced pain sensitivity (hyperalgesia), in part a consequence of increased excitability of central neurons in the spinal cord. ${ }^{9}$

Piroxicam is a NSAID used for postoperative pain relief. Piroxicam inhibits COX-1 and COX-2 and have antiinflammatory, analgesic, and antipyretic activity. Piroxicam is absorbed completely after oral administration and undergoes enterohepatic recirculation. Estimates of the half-life in plasma have been variable; the average is roughly 50 hours. The advantage of using intramuscular piroxicam is its long duration of action. It can inhibit activation of neutrophils, apparently independently of its ability to inhibit cyclooxygenase; hence, additional anti-inflammatory action is also achieved. $^{9}$

Tramadol is a synthetic codeine analog that is a weak $\mu$ opioid receptor agonist. In the treatment of mild-tomoderate pain, tramadol is as effective as morphine or meperidine. Intramuscular tramadol has $100 \%$ bioavailability and rapid onset of action. There is no ceiling dose for tramadol; therefore, pain management can be individually tailored to patient/pain response. Additionally, it also works by inhibiting reuptake of norepinephrine and serotonin. Thus, it provides additional advantage to prefer it for postoperative analgesia. There is no significant risk of addiction with short term use of tramadol for postoperative pain management. Respiratory depression appears to be less than equi-analgesic doses of morphine and is reversible by naloxone. The degree of constipation is less than that seen after equivalent doses of codeine. ${ }^{10}$

Postoperative pain management is important for prevention of postoperative complications. Most of the studies done on similar subjects have been done in western population but Indian subjects are ethnically different from our Caucasian counterpart, therefore, by this study, we want to establish an epidemiological data regarding postoperative analgesia and analgesic being used in our hospital. This study dealt with comparative study of tramadol and piroxicam as analgesic in first post-operative 72 hours in patients operated for inguinal hernia and hydrocele. The idea beyond this study is to get an evidence based appropriate analgesic for postoperative pain.

\section{METHODS}

This study was a hospital based prospective, randomized, comparative, observational study done over a period of one year. Patients operated for hydrocele and inguinal hernia were included in the study after applying the inclusion and exclusion criteria. Written informed consent was taken from every patient before entry in the trial. Simple random sampling was done for the allocation of group. For the purpose of study, equal numbers of patients were randomly allocated equally between two groups.

Drug protocol followed in each group:

Group A (67 patients): Injection tramadol $100 \mathrm{mg}$ intramuscular every 6 hours for 72 hours.

Group B (67 patients): Injection piroxicam $20 \mathrm{mg}$ intramuscular every 24 hours for 72 hours.

Same drug preparation of a particular pharmaceutical company was used in each drug group to prevent the difference in the drug response due to difference in formulations. Patients were subjected to thorough history, clinical examination, biochemical investigations and detailed preanaesthetic assessment. Pain assessment was done by using visual analog scale (VAS). ${ }^{11}$

No analgesia was given to the subjects in the immediate postoperative period. For the initial post-operative 72 hours, analgesic drugs were given according to the drug protocol only. No any other analgesic drug or drug which 
can interfere with pain perception of the patient was given in initial post-operative 72 hours.

Patients operated for inguinal hernia and hydrocele were allocated to receive either tramadol or piroxicam as an intramuscular injection after significant pain (VAS > 3). Subject was kept under observation till the onset of pain. After the onset of pain, detailed evaluation of the pain was done. After the evaluation of the pain, we assessed the intensity of pain by using visual analog scale. After the initial pain assessment of the subject in the preanalgesic period, intramuscular analgesic agent was administered to the patient depending on the group to which the patient belonged.

Patients were regularly assessed for the post-operative pain relief thrice a day (at 8 hours, 16 hours, 24 hours, 32 hours, 40 hours, 48 hours, 56 hours, 64 hours and 72 hours assigning entry of patient in ward after surgery as 0 hours).

Worst pain in between two readings was asked to assess whether there was increase in pain intensity in between this period. If there was marked increase in the pain intensity in the inter dose interval i.e. increase in the visual analog scale score by more than $10 \mathrm{~mm}$, additional dose of analgesic agent was to be administered and such patient was to be excluded from the study. Patient was kept under observation for the whole period of initial post-operative 72 hours for any post-operative complication, which in case, if present, was to be excluded from the study. The study was treated with the intention to treat. Any side effect was carefully noted. Compliance to the drug was assured since the drug was injected intramuscularly under direct supervision in the hospitalized patient. The data so collected was tabulated and subjected to statistical analysis using Statistical Package for Social Sciences (SPSS). The confidence limit of the study was kept at $95 \%$, hence a "p" value less than 0.05 indicated a statistically significant association.

\section{RESULTS}

In patients operated for hernia and hydrocele ,in the first 24,48 and 72 hours of postoperative period, mean VAS scores differed significantly between piroxicam Vs. tramadol $(\mathrm{p}<0.05)($ Table 1$)$.

In patients operated for hernia, in the first 24, 48 and 72 hours of postoperative period, mean VAS scores differed significantly between piroxicam vs. tramadol $(\mathrm{p}<0.001)$ (Table 2).

In patients operated for hydrocele, in the first 24 hours of postoperative period, mean VAS scores differed significantly $(\mathrm{p}<0.001)$ but in the first 48 and 72 hours of postoperative period, mean VAS scores did not differ significantly between piroxicam Vs. tramadol ( $\mathrm{p}=0.151 \&$ $\mathrm{p}=0.125$ respectively) (Table 3 ).
Piroxicam has the advantage of requiring lesser frequency of administration than tramadol due to prolonged duration of action.

Table 1: Mean VAS scores at 24, 48 and 72 hours in different drug groups operated for inguinal hernia as well as hydrocele.

\begin{tabular}{|llll|}
\hline $\begin{array}{l}\text { Duration of } \\
\text { treatment }\end{array}$ & Value & \multicolumn{2}{l|}{ Tramadol vs. piroxicam } \\
\hline 24 hours & Mean & $2.5 \pm 0.24$ & $2.02 \pm 0.34$ \\
\cline { 2 - 4 } & T-value & 3.6 & \\
\cline { 2 - 4 } & P-value & $<0.05$ & \\
\hline 48 hours & Mean & $1.8 \pm 0.33$ & $1.52 \pm 0.26$ \\
\cline { 2 - 4 } & T-value & 5.41 & \\
\cline { 2 - 4 } & P-value & $<0.001$ & \\
\hline 72 hours & Mean & $1.04 \pm 0.32$ & $0.88 \pm 0.18$ \\
& T-value & 3.6 & \\
\cline { 2 - 4 } & P-value & $<0.05$ & \\
\hline
\end{tabular}

Table 2: Mean VAS scores at 24, 48 and 72 hours in different drug groups operated for inguinal hernia.

\begin{tabular}{|llll|}
\hline $\begin{array}{l}\text { Duration of } \\
\text { treatment }\end{array}$ & Value & \multicolumn{2}{c|}{ Tramadol vs. piroxicam } \\
\hline \multirow{3}{*}{24 hours } & Mean & $2.5 \pm 0.04$ & $2.09 \pm 0.29$ \\
\cline { 2 - 4 } & T-value & 9.11 & \\
\cline { 2 - 4 } & P-value & $<0.0001$ & \\
\hline \multirow{3}{*}{48 hours } & Mean & $2.0 \pm 0.27$ & $1.7 \pm 0.13$ \\
\cline { 2 - 4 } & T-value & 5.41 & \\
\cline { 2 - 4 } 72 hours & P-value & $<0.001$ & \\
\hline \multirow{3}{*}{7 Mean } & $1.12 \pm 0.2$ & $1.0 \pm 0.11$ \\
\cline { 2 - 4 } & T-value & 5.48 & \\
\cline { 2 - 4 } & P-value & $<0.0001$ & \\
\hline
\end{tabular}

Table 3: Mean VAS scores at 24, 48 and 72 hours in different drug groups operated for hydrocele.

\begin{tabular}{|llll|}
\hline $\begin{array}{l}\text { Duration of } \\
\text { treatment }\end{array}$ & Value & \multicolumn{2}{c|}{ Tramadol vs. piroxicam } \\
\hline \multirow{3}{*}{24 hours } & Mean & $2.45 \pm 0.25$ & $1.91 \pm 0.49$ \\
\cline { 2 - 4 } & T-value & 5.08 & \\
\cline { 2 - 4 } & P-value & $<0.0001$ & \\
\hline \multirow{3}{*}{48 hours } & Mean & $1.59 \pm 0.14$ & $1.32 \pm 0.17$ \\
\cline { 2 - 4 } & T-value & 1.47 & \\
\cline { 2 - 4 } 72 hours & P-value & 0.151 & $0.71 \pm 0.12$ \\
& Mean & $0.81 \pm 0.33$ & \\
\cline { 2 - 4 } & T-value & 1.55 & \\
\cline { 2 - 3 } & P-value & 0.125 & \\
\hline
\end{tabular}

\section{DISCUSSION}

Piroxicam and tramadol both are suitable for the treatment of pain during outpatient extracorporeal lithotripsy. ${ }^{12}$ Single dose of IM tramadol and IM piroxicam have the same analgesic efficacy for postoperative pain relief after caesarean delivery. ${ }^{13}$ In contrast to this, our observation 
concludes that piroxicam (which is also NSAID like diclofenac) and tramadol, both have analgesic effect but analgesic efficacy of piroxicam in first 24 hours is significantly greater than tramadol.

Piroxicam is a NSAID which is widely used to relieve pain with or without inflammation. NSAIDs inhibit the enzyme cyclooxygenase and thereby, inhibit the synthesis of prostaglandins which are the major mediators responsible for pain and inflammation. NSAIDs also inhibit leukocytes migration \& function and reduce the formation of superoxide radicals. ${ }^{14}$ Thus, NSAIDs become particularly useful in conditions where a degree of tissue inflammation contribute to pain. Postoperative nociceptive impulses are generated not only by the surgical procedure itself, but also by the action of proteolytic and inflammatory agents released intro wound tissues. ${ }^{15}$ Thus, the mechanism of action of NSAIDs justifies the observation of a greater analgesic effect than that of tramadol.

Tramadol has analgesic efficacy due to weak $\mu$ agonistic action with additional mechanism of action i.e. the inhibition of reuptake of both 5-HT and noradrenaline together with presynaptic stimulation of 5-HT release. ${ }^{16}$ Tramadol does not have any action on prostaglandins.

Further, it has been shown that tramadol is effective in mild to moderate pain than in severe post-operative pain. ${ }^{17}$ Patients operated for hydrocele had minimal tissue injury and pain after 24 hours was of mild to moderate intensity. This correlates with the fact that there was no significant difference in the analgesic efficacy of tramadol from piroxicam after 48 and 72 hours in patients operated for hydrocele. First 24 hours period was associated with severe pain and so there was significant difference in analgesic efficacy.

As per Oxford league table of analgesic efficacy for moderate to severe pain, oral tramadol $100 \mathrm{mg}$ has NNT of 4.8 in comparison to oral piroxicam $20 \mathrm{mg}$ of $2.7 .{ }^{18}$ NNT is numbers needed to treat with an additional analgesic due to pain relief less than $50 \%$. Thus, a high NNT of tramadol reflects lesser efficacy than piroxicam. It supports our observation of greater efficacy of piroxicam over tramadol in first 24 hours in hydrocele surgery and in 48 and 72 hours also after surgery for hernia.

Tramadol had been found to be ineffective for postoperative orthopedic pain. ${ }^{19}$ Tramadol was found to have less analgesic efficacy and an increased risk of adverse effects compared with NSAID for the relief of pain after operations on the third molars. ${ }^{20}$ An RCT comparing single dose of tramadol and hydrocodoneacetaminophen in 68 patients with soft-tissue pain found significantly lower pain scores in patients receiving hydrocodone-acetaminophen, even using an inadequate dose of $5 \mathrm{mg}$ of hydrocodone with $500 \mathrm{mg}$ of acetaminophen. $^{21}$ Central response to stimuli may be modulated by NSAIDs-induced inhibition of prostaglandin synthesis in the spinal cord. ${ }^{22}$

\section{CONCLUSION}

Piroxicam provides better and effective analgesia in acute post-operative pain along with the advantage of requiring lesser frequency of administration than tramadol.

Funding: No funding sources

Conflict of interest: None declared

Ethical approval: The study was approved by the Institutional Ethics Committee

\section{REFERENCES}

1. Mersky H. Pain terms: a list with definitions and notes on usage. Recommended by the IASP subcommittee on taxonomy. Pain. 1979;6:249-52.

2. Rathmell JP, Howard HL. Pain: pathophysiology and management. In: Longo DL, Fauci AS, Kasper DL, Hauser SL, Jameson J, Loscalzo J. eds. Harrison's principles of internal medicine. 19 ed. New York, NY: McGraw-Hill; 2015:87.

3. Ryhanen P, Adamski J, Puhakka K. Post-operative pain relief in children. Anaesthesia. 1994;49(1):5761.

4. Rahman MH, Beattie J. Managing post-operative pain. The Pharm J. 2005;275:145-8.

5. Jarrett PEM. Day case surgery. Surgery. 1995;13(1):5-7.

6. Wantz GE. Ambulatory hemia surgery. Br J Surg. 1989;76(12):1228-9.

7. Munro HM, Riegger LQ, Reynolds PI, Wilton NCT, Lewis IH. Comparison of the analgesic and emetic properties of ketoralac and morphine for paediatric outpatient strabismus surgery. $\mathrm{Br} \mathrm{J}$ Anaesth. 1994;72(6):624-8.

8. Moffat AC, Kenny GNC, Prentice JW. Postoperative nefopam and diclofenac. Anaesth. 1990;45(4):302-5.

9. Grosser T, Smyth E, Fitzgerald GA. antiinflammatory, antipyretic, and analgesic agents; pharmacotherapy of gout. In: Brunton LB, Chabner BA, Knollman BC, eds. Goodman \& Gilman's The Pharmacological Basis of Therapeutics. $12^{\text {th }}$ ed. New York, NY: McGraw-Hill; 2011: 989-990.

10. Duthie DJ. Remifentanil and tramadol. Br J Anaesth. 1998;81(1):51-7.

11. Gallagher EJ, Bijur PE, Latimer C, Silver W. Reliability and validity of a visual analog scale for acute abdominal pain in the ED. Am J Emerg Med. 2002;20(4):287-90.

12. Andréou A, Sibert L, Montes R, Hacpille L, Pfister C, Grise P. Randomized study comparing piroxicam analgesia and tramadol analgesia during outpatient electromagnetic extracorporeal lithotripsy. Progres en Urologie. 2006;16(2):155-9.

13. Farshchi A, Ghiasil G. Comparison the analgesic effects of single dose administration of tramadol or 
piroxicam on postoperative pain after cesarean delivery. Acta Medica Iranica. 2010:48(3):148-53.

14. Rational use of NSAIDs for musculoskeletal disorders. Drug Ther Bull. 1994;32(12):91-5.

15. Tverskoy M, Cozacov C, Ayache M, Bradley EL Jr, Kissin I. Post-operative pain after inguinal herniorraphy with different types of anaesthesia. Anesth Analg. 1990;70(1):29-35.

16. Vickers MD, Paravicini D. Comparison of tramadol with morphine for postoperative pain following abdominal surgery. Eur J Anaesthesiol. 1995;12(3):265-71.

17. Demiraran Y, Kocaman B, Akman RY. A comparison of the postoperative analgesic efficacy of single-dose epidural tramadol versus morphine in children. Br J Anaesth. 2005;95(4):510-3.

18. Oxford league table of analgesic efficacy. http://www.medicine.ox.ac.uk/bandolier/booth/painp ag/Acutrev/Analgesics/lftab. Accessed on 25 February, 2016.
19. Stubhaug A, Grimstad J, Breivik H. Lack of analgesic effect of 50 and $100 \mathrm{mg}$ oral tramadol after orthopaedic surgery: a randomized, double-blind, placebo and standard active drug comparison. Pain. 1995;62(1):111-8.

20. Isiordia-Espinoza MA, de Jesús Pozos-Guillén A, Aragon-Martinez $\mathrm{OH}$. Analgesic efficacy and safety of single-dose tramadol and non-steroidal antiinflammatory drugs in operations on the third molars: a systematic review and meta-analysis.Br J Oral Maxillofac Surg. 2014;52(9):775-83.

21. Turturro MA, Paris PM, Larkin GL. Tramadol versus hydrocodone-acetaminophen in acute musculoskeletal pain: a randomized, double-blind clinical trial. Ann Emerg Med. 1998;32(2):139-43.

22. White PF. The role of nonopioid analgesic techniques in the management of pain after ambulatory surgery. Anesth Analog. 2002;94(3):577-85.

Cite this article as: Shukla AK, Raja M, Srivastav AK. Comparative study of tramadol and piroxicam as analgesic for postoperative pain in patients operated for inguinal hernia and hydrocele. Int J Basic Clin Pharmacol 2016;5:312-6. 